\title{
ACÚMULO DE K E NA EM AGUAPÉ CULTIVADAS EM EFLUENTE DE ETE DOMÉSTICA
}

Thadeu Henrique Novais Spósito'; Camila Dias Pinaffi²; Ana Paula Jambers Scandelai³ Carlos Henrique dos Santos ${ }^{2}$

${ }^{1}$ Universidade Estadual Paulista - UNESP, Doutorado em Agronomia, Ilha Solteira, SP. ${ }^{2}$ Universidade do Oeste Paulista UNOESTE, Mestrado em Meio Ambiente e Desenvolvimento Regional, Presidente Prudente, SP. ${ }^{3}$ Universidade Estadual de Maringá - UEM, Doutorado em Engenharia Química, Maringá, PR.. E-mail: camila_pinaffi@hotmail.com

\section{RESUMO}

Este estudo objetivou investigar o potencial do aguapé na remoção de sódio ( $\mathrm{Na}$ ) e potássio (K) de efluente doméstico. Os tratamentos adotados foram: $\mathrm{T} 1=100 \%$ água; $\mathrm{T} 2=25 \%$ efluente; $\mathrm{T} 3=$ $50 \%$ efluente; $\mathrm{T} 4=75 \%$ efluente e T5 $=100 \%$ efluente. Analisou-se a condutividade elétrica (Ce), a concentração de $\mathrm{K}$ e Na no efluente, a massa seca e o acúmulo destes elementos na planta. A Ce, o $\mathrm{K}$ e Na aumentaram com o aumento da concentração de efluente, porém não limitaram o desenvolvimento das plantas. A concentração de $\mathrm{K}$ foi inferior à de $\mathrm{Na}$ no $\mathrm{T} 5$, entretanto, as plantas apresentaram maior acúmulo de $\mathrm{K}$ no tecido, nas mesmas condições. Dessa forma, o aguapé apresentou potencial como agente filtrante em efluentes domésticos.

Palavras-chave: plantas aquáticas, macrófitas, polimento de efluente, poluição das águas, absorção de nutrientes.

\section{ACCUMULATION OF K AND NA IN WATER HYACINTH PLANTS GROWN DOMESTIC EFFLUENT}

\begin{abstract}
The aim of this study was to investigate the potential of the water hyacinth in the removal of sodium $(\mathrm{Na})$ and potassium $(\mathrm{K})$ from domestic effluent. The treatments adopted were: $\mathrm{T} 1=100 \%$ water; $\mathrm{T} 2=25 \%$ effluent; $\mathrm{T} 3=50 \%$ effluent; $\mathrm{T} 4=75 \%$ effluent and $\mathrm{T} 5=100 \%$ effluent. The electrical conductivity (Ce), the $\mathrm{K}$ and $\mathrm{Na}$ concentration of the effluent, dry mass and the accumulation of these elements in the plant were analyzed. $\mathrm{Ce}, \mathrm{K}$ and $\mathrm{Na}$ increased with increasing effluent concentration, but did not limit plant development. The concentration of $K$ was lower than that of $\mathrm{Na}$ in $\mathrm{T5}$, however, the plants presented greater accumulation of $\mathrm{K}$ in the tissue under the same conditions. Therefore, the water has potential as a filtering agent in domestic effluents.
\end{abstract}

Keywords: aquatic plants, macrophytes, effluent polishment, water pollution, absortion of nutrients.

\section{INTRODUÇÃO}

O tratamento inadequado dos esgotos domésticos é um dos maiores problemas ambientais, contribuindo para a poluição dos recursos hídricos e de risco à saúde pública. $\mathrm{O}$ sódio $(\mathrm{Na})$ e o potássio $(\mathrm{K})$, apesar de estarem presente em águas naturais, podem ter suas concentrações aumentadas em função do lançamento de efluentes domésticos e agrícolas (CETESB, 2009).

Com o intuito de amenizar os impactos ambientais de efluentes e concentrações destes elementos químicos em águas superficiais e subterrâneas, buscam-se alternativas de tratamentos que considerem a viabilidade e a disponibilidade de recursos e o atendimento às legislações ambientais (HUSSAR; BASTOS, 2008). Dentre as opções, têm-se as macrófitas aquáticas, como o aguapé (Eichhornia crassipes), as quais possuem capacidade de melhorar a qualidade de 
ambientes poluídos pela absorção, direta ou combinada (mecanismos físicos, químicos e biológicos), de nutrientes (HENRY-SILVA; CAMARGO, 2008).

O aguapé alcança seu crescimento máximo em ambientes lênticos e com altas concentrações de nutrientes (KOBAYASHI et al., 2008). Assim, resistem às águas poluídas com variações de nutrientes, $\mathrm{pH}$ e substâncias tóxicas. Podem, ainda, fixar, em seus tecidos, nutrientes em quantidades superiores à sua necessidade, bem como elementos químicos estranhos ao seu metabolismo (SALATI et al., 2003), como verificado em estudos anteriores (GENTELINI et al., 2008; HENRY-SILVA; CAMARGO, 2008; LACERDA et al., 2012; SHAH et al., 2015).

Neste contexto, este estudo objetiva avaliar a eficiência do aguapé na redução de $\mathrm{Ce}, \mathrm{Na} e$ $K$ de efluente doméstico, de diferentes concentrações, bem como o acúmulo destes elementos no tecido vegetal das plantas.

\section{METODOLOGIA}

O experimento foi conduzido de março a abril de 2013, na Estação de Tratamento de Esgoto (ETE), localizada no distrito de Montalvão, Presidente Prudente/SP. A ETE está localizada a $475 \mathrm{~m}$ de altitude, em uma região de clima definido como Cwb, ou seja, quente, com inverno seco, verão chuvoso e brando, conforme classificação de Köppen.

O efluente foi coletado na lagoa da ETE e distribuído em 25 caixas de PVC $\left(0,32 \mathrm{~m}^{3}\right)$. Os tratamentos adotados foram: $\mathrm{T} 1=100 \%$ de água; $\mathrm{T} 2=25 \%$ de efluente; $\mathrm{T} 3=50 \%$ de efluente; $\mathrm{T} 4$ $=75 \%$ de efluente e T5 $=100 \%$ de efluente, ordenados em delineamento inteiramente casualizado, com parcelas subdivididas, e cinco repetições. As parcelas constituíram os tratamentos e as subparcelas, os períodos de coleta do efluente para análise química $(7,14,21$ e 28 dias).

O efluente da ETE e a água de diluição utilizados nos tratamentos foram submetidos à caracterização de $\mathrm{Na}$ e K, conforme métodos adaptados de Malavolta et al. (1997). Os aguapés, coletados no manancial do rio Santo Anastácio, em Presidente Prudente/SP, caracterizados como plantas jovens, com sistema radicular abundante, com 8 a 12 folhas de aparência uniforme e altura de 12 a $15 \mathrm{~cm}$, foram submetidas à aclimatação ambiental em caixas com água no local do experimento, durante uma semana. Posteriormente, 15 exemplares foram transferidos para seus respectivos tratamentos, mantendo-se uma taxa de ocupação de $80 \%$ da área do recipiente, conforme indicado por Henry-Silva e Camargo (2008).

Durante o período experimental, foram coletadas, semanalmente, 25 amostras de efluente, sendo uma amostra por caixa. Além destas, foram coletadas cinco amostras do efluente da ETE, para o monitoramento da qualidade do tratamento da lagoa (preliminar e biológico), assim divididas: à montante, à jusante e nos terços inicial, médio e final da lagoa.

A determinação da concentração de $\mathrm{K}$ e $\mathrm{Na}$ no efluente foi feita pelos métodos de fotometria de emissão atômica em chama e espectrofotometria de absorção atômica, respectivamente (MALAVOLTA et al., 1997). As leituras de condutividade elétrica (Ce) do efluente foram realizadas em condutivímetro, modelo HI2300/Hanna Instruments.

Aos 28 dias, período médio de desenvolvimento máximo do aguapé nestas condições, o material vegetal foi coletado, lavado com detergente neutro e água deionizada, seco em estufa com circulação forçada de ar, a $65{ }^{\circ} \mathrm{C}$ por $72 \mathrm{~h}$, e moído em moinho tipo Willey. Posteriormente, $0,4 \mathrm{~g}$ da massa seca foi submetida à digestão nítrica-perclórica, em bloco digestor a $250{ }^{\circ} \mathrm{C}$, para determinação dos seus teores totais de $\mathrm{K}$ e Na, de acordo com Malavolta et al. (1997).

Os resultados foram submetidos à análise de variância (ANOVA) e à comparação das médias pelo Teste de Tukey, ao nível de $5 \%$ de probabilidade. 


\section{RESULTADOS E DISCUSSÃO}

As médias de $\mathrm{K}, \mathrm{Na}$ e Ce obtidas no efluente e na água de diluição foram, respectivamente, $13 \mathrm{mg} \mathrm{L}^{-1}, 87 \mathrm{mg} \mathrm{L}^{-1}$ e $503 \mu \mathrm{cm}^{-1}$ (efluente) e $1 \mathrm{mg} \mathrm{L}^{-1}, 0,6 \mathrm{mg} \mathrm{L}^{-1}$ e $197 \mu \mathrm{Sm}^{-1}$ (água), evidenciando a elevada presença desses elementos no efluente e a necessidade de sua redução.

Nas Figuras 1, 2 e 3 são apresentadas, respectivamente, as concentrações dos sais potássio $(\mathrm{K})$ e sódio $(\mathrm{Na})$ e os valores de condutividade elétrica $(\mathrm{Ce})$, obtidos nas diferentes concentrações de efluente e épocas de coleta.

Figura 1. Teor de $\mathrm{K}$ disponível $\left(\mathrm{mg} \mathrm{L}^{-1}\right)$ nos efluentes $(0$ a $100 \%)$, em quatro épocas de coleta. Ajustes significativos $\left(0,01<p<0,05^{* *}\right)$

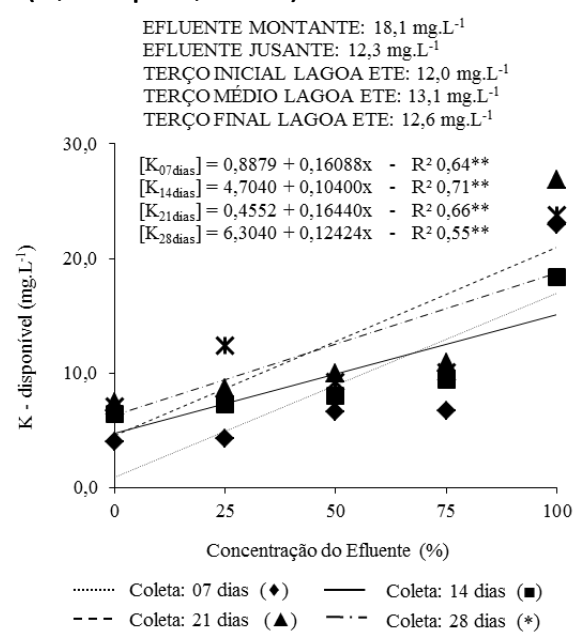

Figura 2. Teor de $\mathrm{Na}$ disponível ( $\mathrm{mg} \mathrm{L}^{-1}$ ) nos efluentes $(0$ a $100 \%)$, em quatro épocas de coleta. Ajustes significativos $\left(0,01<p<0,05^{* *}\right)$

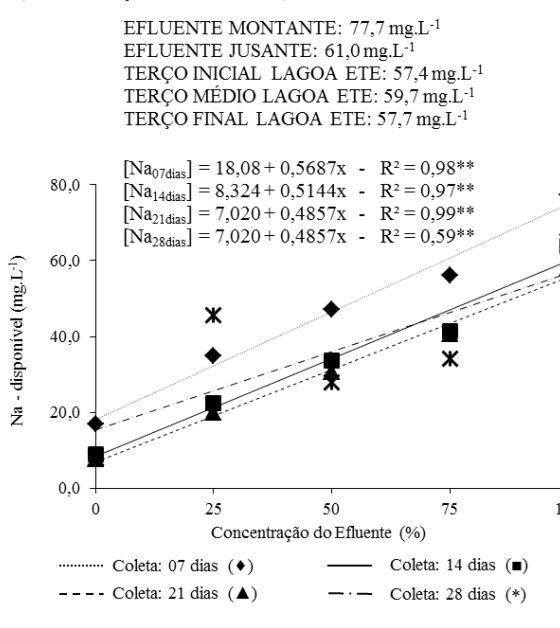

Figura 3. Condutividade elétrica $\left(\mu \mathrm{S} \mathrm{cm}^{-1}\right)$ nos efluentes (0 a $100 \%$ ), em quatro épocas de coleta. Ajustes significativos $(0,01<p<0,05 * *)$

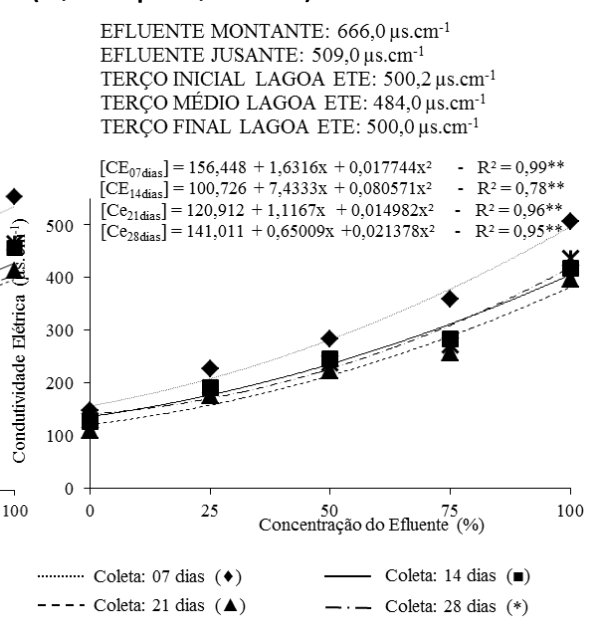

Pela Figura 1, verifica-se que as concentrações de $\mathrm{K}$ disponível no efluente aumentaram com o aumento da sua concentração, sendo que, aos 28 dias, estes valores, nas concentrações de $25 \%, 50 \%, 75 \%$ e $100 \%$, foram $49 \%, 99 \%, 148 \%$ e $197 \%$ superiores ao tratamento com apenas água. Esse aumento ocorreu, provavelmente, em função da absorção de água e nutrientes presentes nos efluentes pelo aguapé, uma vez que, após o período de aclimatação às condições ambientais locais, as plantas apresentaram maior crescimento. Os resultados indicaram ainda, que, apesar da absorção de $\mathrm{K}$ pelas plantas, o mesmo não apresentou redução de concentração no tratamento com $100 \%$ de efluente e, tampouco, entre as épocas de coleta.

Entretanto, observa-se na Figura 2 que, no mesmo período, a absorção de Na foi elevada, indicando que as plantas podem ter reduzido a absorção do $\mathrm{K}$ em detrimento do $\mathrm{Na}$ e, assim, substituindo-o pelo $\mathrm{Na}$ em funções específicas no metabolismo. Este fato pode, ainda, justificar o aumento da concentração de K observada. Verifica-se, ainda, que a concentração de $\mathrm{Na}$ aumentou significativamente com a proporção do efluente, com destaque para o tratamento com $100 \%$ de efluente, aos 28 dias, em que a concentração de Na foi $267 \%$ maior que o manejo com água. A absorção de Na pelas plantas não causou injúrias no tecido vegetal e o aguapé se adaptou bem ao ambiente, principalmente no tratamento mais concentrado.

$\mathrm{Na}$ Figura 3, a qual apresenta os valores de condutividade elétrica (Ce), observa-se que o seu aumento foi proporcional à elevação da concentração do efluente, em todos os períodos de avaliação, sendo observada maior Ce no tratamento mais concentrado. A redução da Ce pode não ter sido maior, no decorrer dos dias, em função da redução do volume de água dos recipientes, proporcionado pela elevada taxa de transpiração das plantas e da evaporação direta da água para a atmosfera. 
Na condição inicial, captado da lagoa, o efluente apresentou concentração de Na de 87,2 $\mathrm{mg} \mathrm{L}^{-1}$ e Ce de $503 \mu \mathrm{S} \mathrm{cm}^{-1}$. Todavia, os valores de Ce diminuíram no decorrer dos períodos, sendo que, após 28 dias, se apresentou abaixo dos $400 \mu \mathrm{sm}^{-1}$ no tratamento com $100 \%$, sem que as plantas apresentassem sintomas visuais de toxidez.

A Ce é um parâmetro de importante conhecimento, uma vez que viabiliza informações sobre a disponibilidade de nutrientes, ainda, é uma medida indireta da concentração de poluentes (MARTINS et al., 2007). Conforme a CETESB (2009), níveis superiores a $100 \mu \mathrm{sm}^{-1}$ indicam ambientes impactados. Nesta situação, a redução na Ce foi de $20,4 \%$ e o valor final se aproximou dos aceitáveis (CETESB, 2009), uma vez que efluentes com Ce $>4.000 \mu \mathrm{S} \mathrm{cm}^{-1}$, podem ser tóxicos ao aguapé, segundo Lacerda et al. (2012).

$\mathrm{Na}$ Figura 4 é apresentado o acúmulo de $\mathrm{K}$ e $\mathrm{Na}$ pelas plantas submetidas às diferentes concentrações de efluentes. A extração de $\mathrm{K}$ e Na pela massa de matéria seca (MMS) do aguapé e a MMS obtida nas plantas são apresentadas, respectivamente, nas Figuras 5 e 6 .

Figura 4. Acúmulo de $\mathrm{K}$ e $\mathrm{Na}$ (g caixa $^{-1}$ ) na MMS do aguapé, nos efluentes (0 a 100\%).

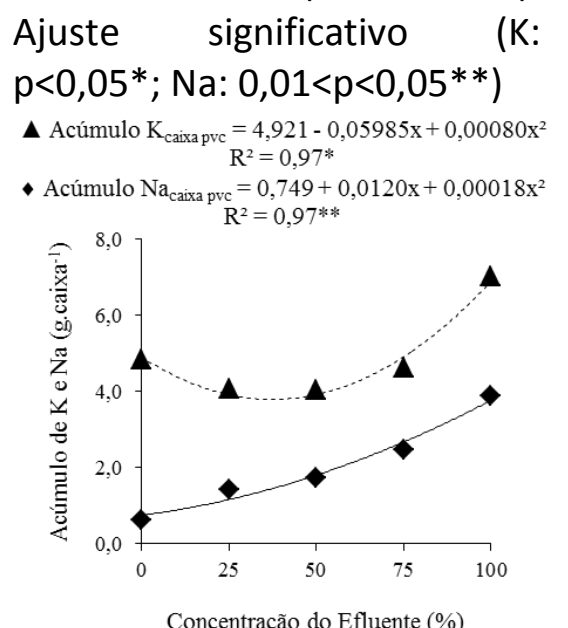

Figura 5. Extração de $\mathrm{K}$ e $\mathrm{Na}$ pela MMS do aguapé $\left(\mathrm{g} \mathrm{m}^{-2}\right)$ nos efluentes (0 a 100\%). Ajuste significativo (K: $\mathrm{p}<0,05^{*} ; \mathrm{Na:} 0,01<\mathrm{p}<0,05^{* *}$ )

$\Delta$ Extração $\mathrm{K}_{\left(\mathrm{m}^{2}\right)}=6,157-0,0971 \mathrm{x}+0,00134 \mathrm{x}^{2}$

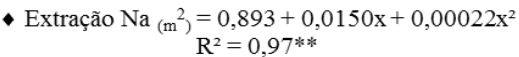

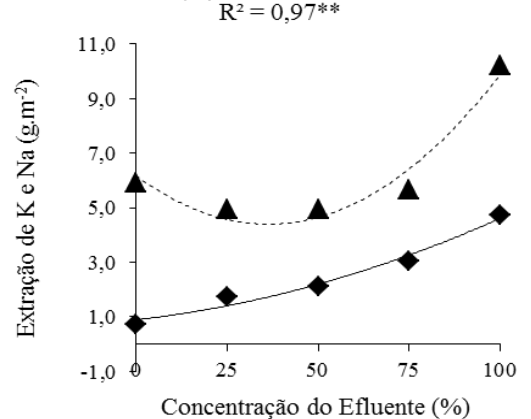

Figura 6. Massa da matéria seca (MMS) das plantas ( $\mathrm{kg} \mathrm{m}$ ${ }^{2}$ ), nos efluentes (0 a 100\%). Ajuste significativo $\left(0,01<\mathrm{p}<0,05^{* *}\right)$

MMS $=0,460371+0,00064629 x+0,000034857 x^{2}$ $\mathrm{R}^{2}=0,94 * *$

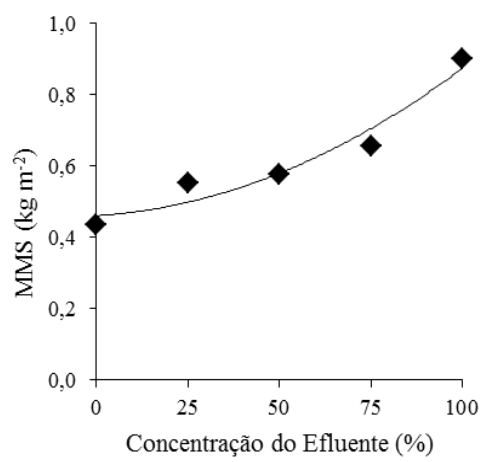

A partir da análise conjunta das características do efluente com o estado nutricional das plantas, apresentada na Figura 4, verifica-se que os aguapés submetidos ao tratamento com $100 \%$ de efluente apresentaram, respectivamente, acúmulo de $\mathrm{K}$ e Na no tecido vegetal de $41 \%$ e $403 \%$ superior aos das plantas cultivadas apenas em água, apesar de não ter ocorrido redução significativa na concentração de K no efluente, conforme apresentado na Figura 1.

Segundo Boyd e Vickers (1971), os aguapés são capazes de absorver e armazenar de 7,2 a $4315 \mathrm{~kg}$ de $\mathrm{K}$, quando bem manejados no ambiente. Contudo, neste estudo, a absorção do K não atingiu este valor, possivelmente devido a fatores interferentes ao processo, como a concentração de $\mathrm{K}$ presente no meio aquoso disponível às plantas e relação de sua concentração com as de outros nutrientes. De acordo com Corrêa et al. (2002), o desenvolvimento de macrófitas dependem de nutrientes como $\mathrm{C}, \mathrm{N}, \mathrm{P}, \mathrm{S}, \mathrm{K}, \mathrm{Ca}, \mathrm{Mg}, \mathrm{Mo}, \mathrm{Mn}$ e $\mathrm{Cu}$, que, mesmo em baixas concentrações, são essenciais à sobrevivência das plantas. Além disso, quando em concentrações acima do limite estabelecido pela máxima demanda nutricional das plantas, os mesmos elementos considerados essenciais podem se tornar tóxicos (MALAVOLTA et al., 1989).

O Na não é um elemento essencial às plantas, entretanto, em determinadas circunstâncias extraordinárias pode substituir o K, uma vez que espécies vegetais que possuem elevado grau de tolerância a sais, podem realizar substituições deste tipo e acumular quantidades significativas de algum outro elemento químico com elevado índice salino (MARSCHNER, 1995). 
Normalmente, o ambiente com elevada salinidade pode causar a perda de água das células, com a diminuição de seu turgor e, ao mesmo tempo, o acúmulo de íons específicos, como o $\mathrm{Na}$ e o $\mathrm{Cl}$ na planta, os quais podem interferir nos processos bioquímicos. O estresse osmótico é, geralmente, imediato e prejudicial à germinação de sementes, emergência e vigor das plântulas, além da absorção de água (FLOWERS; COLMER, 2008; MUNNS; TESTER, 2008). Porém, pelos dados apresentados na Figura 4, não foram observadas injúrias no tecido das plantas.

Os dados de extração de $\mathrm{K}$ e $\mathrm{Na}$ também podem ser estimados em função da área ocupada pelas macrófitas. Na Figura 5, é possível observar o aumento da extração de $\mathrm{K}$ e Na por unidade de área no tratamento com $100 \%$ de efluente. Conforme descrito em Dinardi et al. (2003), em condições naturais, o aguapé possui potencial em remover do ambiente, aproximadamente, $4 \mathrm{~g} \mathrm{~m}$ ${ }^{2}$ de $\mathrm{K}$, valor próximo aos obtidos neste estudo pelos tratamentos com $25 \%$ e $50 \%$ de efluente e inferior ao $100 \%$ de efluente.

A partir da análise da Figura 6, verifica-se que a concentração de efluente foi benéfica para o crescimento das plantas aquáticas, uma vez que houve aumento significativo na produção da massa de matéria seca (MMS) no tratamento com 100\% de efluente. Diante das condições experimentais propostas, as plantas apresentaram aumento na MMS de, aproximadamente, 9\%, $26 \%, 52 \%$ e $89 \%$ para os tratamentos com $25 \%, 50 \%, 75 \%$ e $100 \%$ de efluente, quando comparadas aquelas cultivadas apenas em água.

O aguapé apresenta bom desenvolvimento em regiões de clima quente e, quando não existem limitações nutricionais, o mesmo tem seu desenvolvimento acelerado. A massa natural de uma população de aguapé é variável e, para as condições climáticas brasileiras, pode variar de 250 a $300 \mathrm{mg} \mathrm{ha}^{-1}$ (DINARDI et al., 2003). Segundo os autores, em uma unidade de fitodepuração de $1500 \mathrm{~m}^{2}$, seria possível a retirada mensal de 0,45 a 0,65 mg de material vegetal seco.

Os resultados obtidos neste estudo revelam que a melhor condição nutricional para os aguapés foi obtida com a maior concentração do efluente, uma vez que conduziu à maior produção de MMS pelo aguapé, conforme se pode observar na Figura 6. Segundo Shah et al. (2015) a elevada produtividade destas plantas permite que quantidades significativas de nutrientes sejam extraídas e armazenadas na massa vegetal, a qual pode ser aproveitada como aditivos do solo, fibras para a fabricação de papel, ração animal, produção de biogás, e compostagem.

\section{CONCLUSÃO}

A partir da introdução do aguapé nos tratamentos propostos, verificou-se que os valores de $\mathrm{K}, \mathrm{Na}$ e $\mathrm{Ce}$ aumentaram em função da elevação na concentração do efluente, porém, não foram limitantes ao desenvolvimento do aguapé. Além disso, a concentração de $\mathrm{K}$ contribuiu significativamente como componente da $\mathrm{Ce}$, mas se apresentou inferior à de $\mathrm{Na}$ nas amostras do tratamento com $100 \%$ de efluente. Nas mesmas condições, as plantas apresentaram maior acúmulo de $\mathrm{K}$ do que $\mathrm{Na}$ em seu tecido vegetal, o que indica que o $\mathrm{K}$ também foi absorvido pelas plantas. $O$ aguapé apresentou grande potencial de utilização como agente filtrante do efluente da ETE, contribuindo significativamente na remoção do Na e na diminuição da Ce.

\section{REFERÊNCIAS}

BOYD, C.E., VICKERS, D.H. Variation in the elemental content of Eichhornia crassipes, Hydrobiologia, v. 38, n. 3-4, p. 409-414, 1971. https://doi.org/10.1007/BF00036546

COMPANHIA DE TECNOLOGIA DE SANEAMENTO AMBIENTAL (CETESB). Significado ambiental e sanitário das variáveis de qualidade das águas e dos sedimentos e metodologias analíticas e de amostragem. São Paulo, 2009. 
CORRÊA, M. R.; VELINI, E. D.; ARRUDA, D. P. Teores de metais na biomassa de Egeria densa, Egeria najas e Ceratophyllum demersum. Planta Daninha, v. 20, p. 45-49, 2002. https://doi.org/10.1590/S0100-83582002000400005

DINARDI, A. L.; FORMAGI, V. M.; CONEGLIAN, C. M. R.; BRITO, N. N. de; SOBRINHO, G. D.; TONSO, S.; PELEGRINI, R. Fitorremediação. In: Fórum de Ciências Contábeis, 3 Anais... São Paulo: Faculdades Integradas Claretianas, 2003, p. 1-14.

FLOWERS, T. J.; COLMER, T. D. Salinity tolerance in halophytes. New Phytologist, v. 179, n. 4, p. 945-963, 2008. https://doi.org/10.1111/j.1469-8137.2008.02531.x

GENTELINI, A. L; GOMES, S. D.; FEIDEN, A.; ZENATTI, D.; SAMPAIO, S. C.; COLDEBELLA, A. Produção de biomassa das macrófitas aquáticas Eichhornia crassipes (aguapé) e Egeria densa (egeria) em sistema de tratamento de efluente de piscicultura orgânica. Semina, v. 29, n. 2, p. 441-448, 2008. https://doi.org/10.5433/1679-0359.2008v29n2p441

HENRY-SILVA, G. G.; CAMARGO, A. F. M. Tratamento de efluentes de carcinicultura por macrófitas aquáticas flutuantes. Revista Brasileira de Zootecnia, v. 37, n. 2, p. 181-188, 2008. https://doi.org/10.1590/S1516-35982008000200002

HUSSAR, G. J.; BASTOS, M. C. Tratamento e efluente de piscicultura com macrófitas aquáticas flutuantes. Engenharia Ambiental, v. 5, n. 3, p. 274-285, 2008.

KOBAYASHI, J. T.; THOMAZ, S. M.; PELICICE, F. M. Phosphorus as a limiting factor for Eichhornia crassipes growth in the upper Paraná river floodplain. Wetlands, v. 28, n. 4, p. 905-913, 2008. https://doi.org/10.1672/07-89.1

LACERDA, L. P. de; LANGE, L. C.; FRANÇA, M. G. C. Redução de salinidade em cultivo hidropônico de capim vetiver (Vetiveria zizanioides) e aguapé (Eichhornia crassipes). Revista Aidis de Ingeniería y Ciencias Ambientales: Investigación, Desarrollo y Práctica, v. 5, n. 3, p. 1-10, 2012.

MALAVOLTA, E.; MALAVOLTA. M. L.; CABRAL, C. P.; ANTONIOLLI, F. Sobre a composição mineral do aguapé (Eichornia crassipes). Anais da ESALQ, v. 46, p. 155-162, 1989.

MAlavoltA, E.; VITTI, G. C.; OliveiRA, S. A. Avaliação do Estado Nutricional de Plantas: Princípios e Aplicações. 2. ed. Piracicaba: Ed. Potafós, 1997, 304 p.

MARSCHNER, H. Mineral Nutrition of Higher Plants. 2. ed. London: Ed. Academic Press, 1995, 889 p.

MARTINS, A. P. L.; REISSMANN, C. B.; FAVARETTO, N.; BOEGER, M. R. T.; OlIVEIRA, E. B. Capacidade da Typha dominguensis na fitorremediação de efluentes de tanques de piscicultura na Bacia do Iraí - Paraná. Revista Brasileira de Engenharia Agrícola e Ambiental, v.11, n.3, p.324330, 2007. https://doi.org/10.1590/S1415-43662007000300013

MUNNS, R.; TESTER, M. Mechanisms of salinity tolerance. Annual Review of Plant Biology, v. 59, n. 1, p. 651-681, 2008. https://doi.org/10.1146/annurev.arplant.59.032607.092911 
NIAZ, M.; RASUL, E. Aquatic macrophytes as biological indicators for pollution management studies. IV: Effects of salts present in factory effluent water on chemical and biochemical composition of Eichhornia crassipes and Pistia stratiotes. Pakistan Journal of Biological Sciences, v. 1, n. 3, p.332-334, 1998.

SHAH, M.; HASHMI, H. N.; GHUMMAN, A. R.; ZEESHAN, M. Performance assessment of aquatic macrophytes for treatment of municipal wastewater. Journal of the South African Institution of Civil Engineering, v.57, n.3, p. 18-25, 2015. https://doi.org/10.17159/2309-8775/2015/V57N3A3

SALATI, E.; SALATI FILHO, E.; SALATI, E. Utilização de sistemas de wetlands construídos para tratamento de águas. Biológico, v. 65, n. 1/2, p. 113-116, 2003. 